\title{
Sibling recognition in thirteen-lined ground squirrels: effects of genetic relatedness, rearing association, and olfaction
}

\author{
Warren G. Holmes \\ Psychology Department, University of Michigan, Ann Arbor, Michigan 48109, USA
}

Received April 25, 1983 / Accepted August 16, 1983

\begin{abstract}
Summary. I investigated sibling-sibling recognition in captive thirteen-lined ground squirrels (Spermophilus tridecemlineatus) by cross-fostering lab-born pups shortly after birth. When young reached about 45 days of age, I observed dyadic interactions in a test arena of pairs from four relatedness $\mathrm{X}$ rearing groups, and recorded the frequency of "exploratory" encounters between individuals. Sibs-reared together and nonsibs-reared together exhibited significantly fewer exploratory encounters than either sibs-reared apart or nonsibsreared apart. Young reared together were equally exploratory, regardless of relatedness; similarly, young reared apart, whether they were sibs or nonsibs, showed similar levels of exploration. Thus, the differential treatment of siblings in the lab appears to be based on rearing association and not genetic relatedness per se. I interpret this recognition based on association (rearing familiarity) in the context of the species' social organization and compare my results on S. tridecemlineatus with similar studies on S. beldingi, S. parryii, and $S$. richardsonii. I also used an olfactory impairment technique (zinc sulfate) and found that differential treatment in thirteen-lined ground squirrels was influenced by olfactory cues.
\end{abstract}

\section{Introduction}

Kin recognition abilities represent a group of proximal mechanisms used in the differential treatment of conspecifics. Such mechanisms are important to Hamilton's kin selection hypothesis (Hamilton 1964, 1972; West Eberhard 1975; Holmes and Sherman 1983), and may also be important for the avoidance of extreme inbreeding (Dewsbury 1982; Hoogland 1982) or for achieving a balance between inbreeding and outbreeding (Bateson 1980, 1982, 1983; Shields 1982).

Genetic relatedness underlies many aspects of social behavior in the genus Spermophilus (Family: Sciuridae; reviewed in Michener 1983). For example, kinship affects spatial relationships (Dunford 1977a; Michener 1979, 1981; Sherman 1980, $1981 \mathrm{a}$; McLean 1982, 1984; Murie and Harris 1984; Vestal and McCarley 1984), the frequency of amicable and agonistic interactions (Michener 1973, 1981; Sherman 1980, 1981 b; McLean 1982, 1984; Davis 1984), the likelihood of emitting alarm calls (Dunford 1977b; Sherman 1977; Schwagmeyer 1980), and the antagonists involved in infanticide (McLean 1982, 1983; Sherman 1981 b).

In addition to field research on Spermophilus, studies have also been conducted to uncover the abilities and mechanisms that underlie the differential treatment of kin. Experimental work has been done on (1) dam-offspring (S. richardsonii: $\mathrm{Mi}$ chener and Sheppard 1972; Michener 1974; S. beldingi: Holmes and Sherman 1982), (2) sibling-sibling (S. richardsonii: Sheppard and Yoshida 1971; Davis 1982; S. parryii and $S$. beldingi: Holmes and Sherman 1982), and (3) littermate maternal half-sibling recognition ( $S$. beldingi: Holmes and Sherman 1982). Identification appears to be based on association (e.g., a shared rearing environment) in some cases (dam-offspring in $S$. richardsonii and $S$. beldingi), but recognition in the near absence ( $\leqq 24 \mathrm{~h}$ ) of postnatal association has also been reported (sib-sib in S. richardsonii, $S$. parryii, and $S$. beldingi). For littermate maternal half-sisters in $S$. beldingi, both association and relatedness seem to influence discrimination.

Holmes and Sherman (1982, 1983) described four proximal mechanisms by which kin can be identified (see also Hamilton 1964; Alexander 1979; Hölldobler and Michener 1980; Sherman 
1980; Bekoff 1981). (1) Spatial distribution - individuals recognize locations rather than relatives so that kin are favored as a result of location-specific behavior [e.g., the early parental care of young confined to the nest in some avian species (Hoogland and Sherman 1976; Burtt 1977; Beecher et al. 1981)]. (2) Association - relatives are identified as "familiar" conspecifics (not as kin per se) that associated in "appropriate" social circumstances [i.e., those in which relatedness is not obscured by the intrusion of unrelated (or unequally related) conspecifics]. For example, natal and rearing environments (nests, burrows, or territories) may facilitate kin identification by association (Sheppard and Yoshida 1971; Michener and Sheppard 1972; Michener 1974; Porter et al. 1978; Porter and Wyrick 1979). Cross-fostering, in which unequally related conspecifics associate during rearing, is a technique to investigate sib recognition by the association mechanism (e.g., Porter et al. 1981), and it is used here (see below). (3) Phenotype matching - an individual learns some aspect of its own phenotype or the phenotypes of familiar relatives. Later, the individual matches the learned "template" against the phenotype of a conspecific that it has not previously encountered (Lacy and Sherman 1983). The mechanism requires a correlation between phenotypic and genotypic similarity (Carter-Saltzman and Scarr-Salapatek 1975) and that phenotypic traits learned under one set of circumstances are remembered and used subsequently (Buckle and Greenberg 1981). (4) Recognition alleles - relatives are identified as a result of alleles (or alleles tightly linked to them) that have three joint effects: the expression of a phenotypic marker, the perception of the marker in others, and the dispensation of assistance to possessors of the marker. Consideration of recognition alleles has been more along theoretical than empirical lines (Hamilton 1964; Alexander and Borgia 1978; Alexander 1979; Ridley and Grafen 1981; Dawkins 1982; Rothstein and Barash 1983). An empirical search for such alleles is greatly complicated by the possibility of phenotype matching against one's own phenotype [Salzen and Cornell 1968; Vidal 1982; but see Blaustein (1983)].

Here, I present laboratory data on kin recognition in thirteen-lined ground squirrels ( $S$. tridecemlineatus). By cross-fostering newborns, I examined how genetic relatedness and rearing association affected sibling-sibling recognition in captive, juvenile ground squirrels. My rearing and testing procedure followed Holmes and Sherman (1982) as closely as possible to facilitate inter-specific comparisons. In addition, I used an olfactory-impair- ment technique (zinc sulfate) to determine if olfactory cues were important to the identification process. Field studies (considered below) of S. tridecemlineatus, S. beldingi, S. parryii, and S. richardsonii report differences in social organization (e.g., spatial relationships, frequency of interactions, treatment of kin) that may bear on inter-specific differences in recognition abilities.

\section{Materials and methods}

Subjects, cross-fostering, and rearing. Thirteen female $S$. tridecemlineatus were live-trapped (11-15 May, 1982) at the University of Michigan's Matthaei Botanical Gardens near Ann Arbor, Michigan. Each female was brought into the laboratory and housed individually in a stainless steel cage $(50 \times 15 \times 12 \mathrm{~cm})$ that contained a plywood nestbox $(25 \times 15 \times 12 \mathrm{~cm})$ filled with wood shavings and fitted with a removable top. Purina mouse breeder chow and water were available ad libitum, and lettuce was supplied two or three times per week. Cages were positioned on racks in a $6.1 \mathrm{~m}^{2}$ colony room, maintained at about $20^{\circ} \mathrm{C}$ under a $14 \mathrm{~L}$ : $10 \mathrm{D}$ photoperiod.

Ten of the 13 females gave birth $[\bar{x}=6.4 \pm 0.6$ (SE) pups/ litter; $n=29$ male and 35 female pups; $20-27$ May, 1982] as revealed by daily and sometimes twice daily inspection of nestboxes. Within $24 \mathrm{~h}$ of birth, newborns were sexed, weighed, and toe-clipped for permanent identification.

Cross-fostering of pups between dams created four relatedness $\times$ rearing groups for later recognition tests (see Fig. 1, Holmes and Sherman 1982). When two females produced litters less than $56 \mathrm{~h}$ apart ( 8 of 10 females), two or three pups were taken from each female (6-10 h after the birth of the second litter) and interchanged to create four kinds of dyads (hereafter four "groups"): (1) sibs-reared together (S.RT.), (2) sibs-reared apart (S.RA.), (3) nonsibs-reared together (NS.RT.), and (4) nonsibs-reared apart (NS.RA.). Hereafter, I use "familiar" to refer to pups that were reared together, regardless of their genetic relatedness, and "unfamiliar" to refer to pups that were reared apart, both sibs and nonsibs.

After pup-exchange (which took ca. $15 \mathrm{~min}$ ) was completed for a pair of dams, pups and dams were returned to females' cages in their nestboxes. Fostering did not result in differential mortality (own versus foster pups), and both kinds of pups reached similar weights by weaning $(P>0.1)$. Two dams produced litters when no other females were available for crossfostering (i.e., within the arbitrary $56 \mathrm{~h}$ limit). Their young were handled as if being fostered, including toe-clipping, and returned to their nestboxes, later to be tested in S.RT. or NS.RA. groups.

Pups remained with their biological or foster dam and their cagemates until testing at about 48 days of age (young were weaned at 25-30 days of age). At about 33 days of age, one or two spots of hair dye were applied to each juvenile (young $\geqq 30$ days of age) so that one animal could be distinguished from the other during a dyadic test. However, several juveniles shared similar spots so that dye did not indicate an animal's individual or group identity. When both members of a test pair were marked similarly, body size was used to distinguish them. About one week prior to testing, each ground squirrel was placed alone in the test arena (below) for $3045 \mathrm{~min}$ and allowed to explore freely before being returned to its home cage.

To describe subjects in this study properly, "siblings" refers to uterine (or littermate) siblings (full- or maternal half- 
sibs) because female thirteen-lined ground squirrels are frequently mounted by more than one male during estrus, although it is not known if litters contain offspring sired by more than one male (Schwagmeyer 1984). Movement patterns of male and female $S$. tridecemlineatus during the breeding season have not been described, but a male in the population from which my subjects came typically has a home burrow less than $100 \mathrm{~m}$ from home burrows of females he mates (Schwagmeyer 1979). Because pups were transferred between dams trapped more than $350 \mathrm{~m}$ apart, it seems unlikely that litters were sired by the same male.

Testing for recognition. Recognition abilities were examined by observing pairs of juveniles interact for a 5 -min period in a $1 \mathrm{~m}^{3}$ plywood arena, with a plexiglass front and an opaque dividing partition. Before testing began, each juvenile was placed individually in a numbered holding cage where it remained for 30-50 min when other pairs were being tested. Numbered cages allowed laboratory assistants to bring pairs into the test room in a random order and prevented me (the observer during all tests) from knowing a pair's identity.

To start a test, two ground squirrels were carried from the colony room into the test room in holding cages, and one was placed on each side of the arena's dividing partition. I observed the arena, illuminated by two overhead $100 \mathrm{~W}$ light bulbs, from behind an opaque screen with a viewing slit cut in it. To increase the likelihood that both animals would be active in the arena, I waited until each ground squirrel touched all four sides of its half of the arena during a 3-min pre-test period ( $96 \%$ of all animals placed in the arena). Then I lifted the dividing partition by a rope and pulley system and gave animals 5 min to interact. The 5 -min period began when body contact occurred or when one animal oriented its body toward the other in one of several postures (below).

During a test, I described (into a tape recorder) all instances of social exploration (below), including the initiator and the time when each interaction occurred. Among free-living thirteen-lined ground squirrels, newly emerged juveniles remain associated with their nestmates for the first $7-14$ days aboveground, and then begin interacting regularly with other juveniles living near-by (Rongstad 1965; McCarley 1966; Schwagmeyer 1979). These interactions include frequent nose-to-nose, nose-to-mouth, nose-to-head, nose-to-body, and nose-to-anus contact, which I refer to as "exploratory encounters" [definitions and descriptions of these behaviors in congeners are in Sheppard and Yoshida (1971), Betts (1976), and Steiner (1970)].

In studies of other species, kin recognition has been inferred when individuals (or classes of them) treat each other differentially according to their genetic relatedness. For example, the tendency to swim toward (Blaustein and O'Hara 1981), to school with (Waldman and Adler 1979), to allow passage to (Greenberg 1979), and to avoid biting (Breed 1983; Getz and Smith 1983) close kin over non- or more distant kin have all been used in lab studies of recognition. Here, I used the combined frequency of the five kinds of exploratory interactions (above) as a behavioral measure for "recognition." Prolonged $(\geqq 3 \mathrm{~s}$ ) exploratory encounters might be considered "neutral" or "cohesive," but these occurred infrequently ( $<8 \%$ of all interactions averaged over four groups) and were not included in analyses. I almost never observed "agonistic" interactions [e.g., paw swipe, lateral, lunge strike (Holmes and Sherman 1982)] and rarely did I see "cohesive" encounters [e.g., allogrooming, crawl over (Sheppard and Yoshida 1971)].

Sample sizes were constrained by two factors once pups were weaned. First, I tested approximately equal numbers of male-male, male-female, and female-female pairs in each group
(Table 1). Second, I minimized the number of times one individual was tested as a member of more than one pair in the same group. I was least successful in doing this for the NS.RT. group in which 3 of 19 pairs included the same individual. On the other hand, 50 of the 55 animals were used as a member of a pair in two or more different groups.

Juveniles were tested at $48.5 \pm 2.5 \mathrm{~d}$ of age (mean $\pm \mathrm{SE}$ ) and a weight of $61.7 \pm 2.0 \mathrm{~g}$. In the field, juveniles of this age would be living in or near their natal area and interacting with their nestmates and non-nestmates (Rongstad 1965; McCarley 1966; Schwagmeyer 1979). There were no significant differences in age or weight at testing across the four groups $(P>0.1$ ANOVAs). Arena tests were conducted between 30 June and 11 July, 1982, and each pair was tested only once as earlier work (Holmes and Sherman 1982) found that pairs' behavior was stable over repeated tests at 5-day intervals.

Zinc sulfate treatment. After juveniles' first arena tests, I used zinc sulfate to impair olfaction. Intranasal injection of zinc sulfate causes necrosis and sloughing off of the nasal epithelium and appears to induce peripheral "anosmia" in several species (Alberts 1974). However, I will refer to animals that have been olfactorily "impaired" (behaviorally verified as described below) because "anosmia" has a variety of meanings (Murphy 1976).

I administered zinc sulfate to 12 pairs of familiar and 12 pairs of unfamiliar young (6 sibling and 6 nonsibling pairs in the familiar and unfamiliar group). At about $60 \mathrm{~d}$ of age, each animal was lightly anesthetized with ether and placed on its back in an inclined (ca. $30^{\circ}$ ) position with its head lowered. A blunted 23 ga. needle was used to inject approximately $0.1 \mathrm{ml}$ of $5 \%$ zinc sulfate in $0.9 \%$ saline into each nostril. Excess solution was aspirated at the external nares. An equal number of juveniles was treated like the impaired subjects, but was injected with $0.9 \%$ saline (the control group). Following treatment, each animal was placed individually in a cage for $24 \mathrm{~h}$ before being returned to its home cage. Three or four days after treatment, pairs of impaired and control animals were tested in the arena as described above. During tests, I did not know animals' group or individual identity.

Olfactory impairment was assessed independently by placing one animal at a time in the test arena $24-48 \mathrm{~h}$ after its paired-encounter test. Two perforated metal lids $(53 \mathrm{~cm}$ diameter) were attached to the arena, one covering a jar of peanut butter, a highly preferred food, and the other covering an empty container. Animals administered zinc sulfate spent significantly $(P<0.001)$ less time near $(<5 \mathrm{~cm})$ the peanut butter lid (continuous sampling during a 2 -min test period) than did the controls $(\bar{x}=19 \pm 7.0 \mathrm{~s}$ versus $\bar{x}=75 \pm 8.3 \mathrm{~s}$, respectively). Impaired and control animals' times near the empty container's lid did not differ significantly $(P>0.1)$.

Data analysis. The mean $( \pm \mathrm{SE})$ number per pair of all exploratory interactions combined is reported for each group. These means were compared with a one-way analysis of variance (ANOVA), followed by Scheffe's test to compare each possible pair of means between groups (e.g., S.RT. vs S.RA.). Scheffés test allows post hoc comparisons between groups' means that are not independent and controls $\alpha$ for the fact that multiple comparisons are made. Two-sample comparisons were made with $t$-tests. Because between-group variance was high in a few cases, I also conducted nonparametric tests (e.g., Kruskal-Wallis ANOVA, Mann-Whitney $U$ ) on all data. Results were identical (significant or not significant) for all parametric and nonparametric tests so only parametric results are presented. In all cases, differences were considered significant if $P<0.05 ; P$ values are reported in the text and figures. 


\section{Results}

There was a significant difference across the four groups in the mean number of exploratory encounters during the arena tests $(P<0.001$, ANOVA, Fig. 1). Contrasts between pairs of groups with Scheffe's tests revealed that a familiarity effect (and not one of genetic relatedness) accounted for the across-groups difference. Juveniles reared together, both sibs and nonsibs, showed significantly fewer exploratory encounters than both sib and nonsib pairs reared apart (Fig. 1). Moreover, sibling and nonsibling pairs reared together

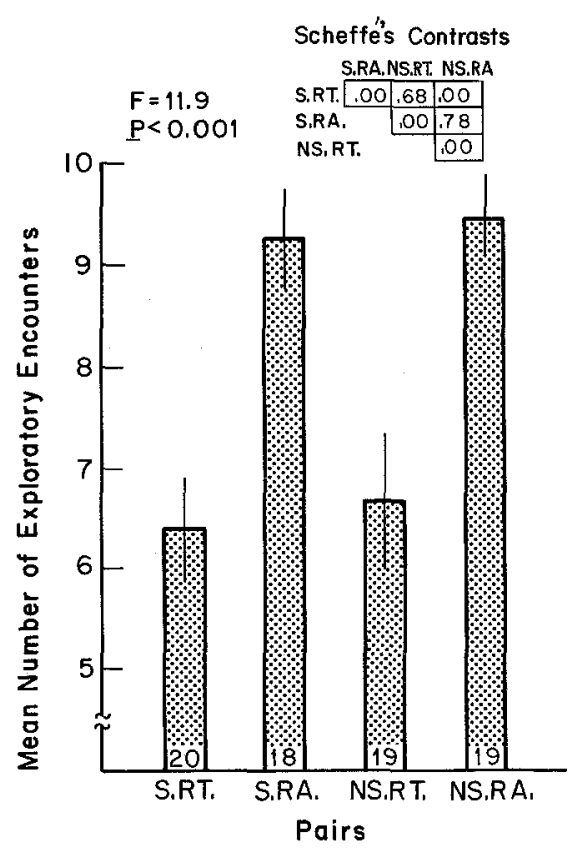

Fig. 1. The mean $( \pm S E)$ frequency of exploratory encounters recorded during 5-min dyadic tests of captive juvenile thirteenlined ground squirrels. Numbers of pairs tested are shown inside bars. Cross-fostering produced the four relatedness $\mathrm{X}$ rearing groups: sibs-reared together (S.RT.), sibs-reared apart (S.RA.), nonsibs-reared together (NS.RT.), and nonsibs-reared apart (NS.RA.). The $F$ value is based on a oneway ANOVA; $P$ values from Scheffés contrasts are shown for comparisons between particular groups. For example, S.RT. were significantly less exploratory than NS.RA. at $P<0.001$, whereas S.RT. did not differ significantly $(P=0.68)$ from NS.RT. did not differ significantly in frequencies of exploratory interactions $(P>0.1)$. I also examined whether or not familiar pairs reared in "pure" litters (sibs only, no in-fostering) differed in exploratory encounters from those reared in "mixed" litters (sibs and nonsibs) and found no significant difference between "pure" and "mixed" litters $(P>0.1)$.

Having found a familiarity effect (young reared together), I compared the frequency of exploratory interactions during the first minute versus the last minute of the arena test for both familiar (reared together) and unfamiliar (reared apart) pairs. For familiar pairs ( $n=39$, sibs and nonsibs combined), the mean number of exploratory encounters during the first minute $(\bar{x}=2.5 \pm 0.1)$ was significantly greater $(P<0.01)$ than the mean number during the last minute $(\bar{x}=0.6 \pm 0.1)$. In contrast, for unfamiliar pairs ( $n=37$, sibs and nonsibs combined), there was no significant change $(P>0.1)$ in frequency from the first $(\bar{x}=2.3 \pm 0.1)$ to the last $(\bar{x}=$ $2.0 \pm 0.2)$ minute.

I did not analyze exploratory interactions according to the sex of the pair tested within each group because the sample sizes seemed inadequate to draw valid conclusions in some instances. However, when pairs in the four groups are partitioned by sex, no clear differences appear within or between the groups due to sex (Table 1).

Treatment with zinc sulfate altered ground squirrels' interactions in the test arena (Fig. 2). First, for both familiar and unfamiliar pairs, the frequency of exploratory encounters after treatment was significantly lower than before treatment $(P<0.001)$. This result is based on tests of the same individuals before and after administration of zinc sulfate. (Data from sibling and nonsibling pairs were combined for familiar and unfamiliar pairs because tests described above showed no effect of genetic relatedness.) Second, in a comparison of familiar pairs with unfamiliar pairs, there was no significant difference $(P>0.1)$ in levels of exploration after treatment with zinc sulfate, whereas a significant difference $(P<0.001)$ did exist before treatment.

Table 1. The frequency of exploratory encounters between captive male-male $(m-m)$, male-female $(m-f)$, and female-female $(f-f)$ thirteen-lined ground squirrels during 5-min dyadic tests

\begin{tabular}{|c|c|c|c|c|c|c|c|c|c|c|c|c|}
\hline & \multicolumn{3}{|c|}{ Sibs-reared together } & \multicolumn{3}{|c|}{ Sibs-reared apart } & \multicolumn{3}{|c|}{ Nonsibs-reared together } & \multicolumn{3}{|c|}{ Nonsibs-reared apart } \\
\hline & $\mathrm{m}-\mathrm{m}$ & $m-f$ & $f-f$ & $\mathrm{~m}-\mathrm{m}$ & $m-f$ & $f-f$ & $\mathrm{~m}-\mathrm{m}$ & $m-f$ & $\mathrm{f}-\mathrm{f}$ & $\mathrm{m}-\mathrm{m}$ & $m-f$ & $f-f$ \\
\hline $\bar{x}$ & 6.7 & 6.2 & 6.4 & 10.5 & 9.0 & 8.2 & 6.0 & 7.0 & 6.7 & 9.8 & 10.5 & 8.2 \\
\hline $\mathrm{SE}$ & 0.5 & 0.9 & 1.0 & 0.7 & 0.5 & 1.3 & 0.9 & 0.6 & 1.1 & 1.1 & 0.5 & 0.3 \\
\hline$n$ & 6 & 6 & 8 & 7 & 6 & 5 & 5 & 7 & 7 & 6 & 7 & 6 \\
\hline
\end{tabular}




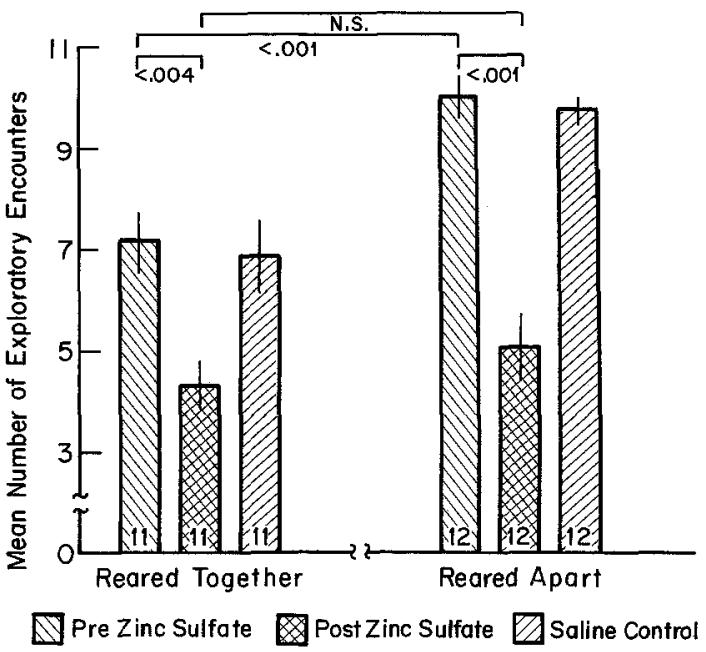

Fig. 2. The effect of olfactory impairment (zinc sulfate) on the mean $( \pm S E)$ frequency of exploratory encounters during dyadic tests of juvenile thirteen-lined ground squirrels reared together or reared apart. Numbers of pairs tested are indicated inside bars. Shown are the frequencies of exploratory encounters before treatment with zinc sulfate, after nasal injection of zinc sulfate, or after injection of saline (control). Also shown are $P$ values for comparisons between particular groups based on $t$-tests. For example, for juveniles reared together, there were significantly fewer exploratory encounters $(P<0.004)$ after the zinc sulfate treatment than before treatment

\section{Discussion}

\section{Sibling recognition in $S$. tridecemlineatus}

Results (Fig. 1) suggest that identification of uterine siblings in captive thirteen-lined ground squirrels is mediated by the association mechanism (see Introduction). Pups reared together, whether biological or foster sibs, treated each other similarly, whereas pups reared apart, regardless of their relatedness to each other, engaged in numerous exploratory interactions (Fig. 1). Thus, differential treatment is based on rearing associations; there is no indication that genetic relatedness per se mediates identification. In addition, neither in utero association nor early ( $\leqq 56 \mathrm{~h}$ ) postnatal association seem crucial to sibling recognition because no difference appeared between S.RA. and NS.RA. in their frequencies of exploratory interactions. Juveniles in the former group shared a common uterine and early postnatal environment, whereas NS.RA. shared neither.

The effect of rearing association on differential treatment is also apparent from between-group comparisons of exploratory encounters that occurred during the first and last minute of arena tests. For familiar pairs, exploratory encounters were significantly less frequent during the last minute than the first minute. For unfamiliar pairs, in contrast, the frequency did not change from the first to the last minute. One interpretation is that exploratory interactions help assess familiarity; past familiarity decreases exploratory interactions. On the other hand, if individuals do not recognize each other as familiar, exploratory interactions continue unabated as unfamiliar juveniles attempt to establish familiarity. Whereas this interpretation is post hoc, the important point is that the behavior of familiar and unfamiliar pairs differed. These differences are apparent when the frequency of all exploratory interactions are considered (Fig. 1), and also when one contrasts first-minute versus last-minute frequencies from familiar and unfamiliar pairs.

\section{Interspecific comparisons of sibling recognition}

Sibling recognition mechanisms in $S$. beldingi and $S$. parryii have also been studied with a cross-fostering and testing procedure like that reported here. Holmes and Sherman (1982) found that in $S$. beldingi and $S$. parryii, pups reared together, whether biological or foster sibs, treated each other similarly, as in S. tridecemlineatus. In contrast to $S$. tridecemlineatus, however, S.RA. in S. beldingi and S. parryii interacted differently (fewer agonistic encounters) than NS.RA. Specifically, unfamiliar sister-sister pairs in both species were significantly less agonistic than unfamiliar, unrelated female-female pairs, whereas relatedness did not lead to differential aggression in male-male or malefemale pairs (Figs. 3 and 5 in Holmes and Sherman 1982). The authors suggested that rearing association alone did not explain sibling recognition in lab tests and that perhaps an additional mechanism was operating - phenotype matching against nestmates' phenotypes or their own phenotype (see Introduction). However, insufficient data were available to examine thoroughly the phenotype matching hypothesis.

Arena tests have also been employed to investigate sibling recognition in captive Richardson's ground squirrels. Sheppard and Yoshida (1971) found little agonistic and frequent cohesive behavior for S.RT. compared to NS.RA. Cross-fostering was not used in their study. On the other hand, Davis (1982) did cross-foster S. richardsonii and reported that S.RT. approached each other more often and "kissed" (naso-oral contact) more often than NS.RT. He also found that S.RA. remained closer to each other, contacted each other more often, and remained in contact longer than NS.RA. All sex-of-pair dyads were combined in Davis' analyses. In regard to a recognition mecha- 
nism, he pointed out that a "genetic recognition system," intra-uterine effects, imprinting, and familiarity based on rearing associations may all have influenced pairs' arena behavior.

Differences in pre-test association among cagemates make it difficult to compare sibling recognition by S. richardsonii (i.e., Davis 1982) with the three other species of ground squirrels that have been cross-fostered in the laboratory. Cagemates were housed together until shortly before testing in S.tridecemlineatus and S. parryii. Cagemate $S$. beldingi were housed together until being put individually into the coldroom to hibernate and were then tested ( 7 months later) shortly after being taken from the coldroom. [Sibling recognition could not be tested in juvenile $S$. beldingi as explained in Holmes and Sherman (1982)]. Finally, cagemate $S$. richardsonii lived together until about 35 days of age, but were then housed individually for approximately $75 \mathrm{~d}$ until they were tested. The 75 days of social isolation experienced by $S$. richardsonii during the non-hibernation season precludes comparisons with the other three species that were not comparably isolated. In fact, Davis (1982) indicàtes that it is difficult to draw inferences from laboratory results about the basis for sibling recognition in free-living $S$. richardsonii because prolonged social isolation during the active season is not characteristic of juveniles in the wild (Davis 1984; Michener 1981).

\section{Social organization and sibling recognition}

Multi-season behavioral studies of individually recognizable, free-living $S$. tridecemlineatus are rare. In a 3-year study of a marked population in Michigan (the same population from which my subjects came), Schwagmeyer (1979) reported that preferential treatment of individuals was restricted to a few categories of conspecifics (dam-offspring and littermate pairs) and was confined to a short period of time (a few weeks after juvenile emergence from natal burrows). Schwagmeyer (1980) focused on alarm calls; she found that they were given almost exclusively by dams during the 3 -week period after emergence of their litters or by littermates themselves, despite adult females having their female kin living within audible range of calls all summer. In addition, social interactions among littermates occurred most frequently during the early post-emergence period as littermates established separate burrow systems 3-4 weeks after coming aboveground. Former nestmates did not appear to treat each other preferentially at one or more years of age even though their home ranges overlapped (Schwagmeyer 1979).

If the spatial and behavioral relationships described by Schwagmeyer $(1979,1980)$ characterize other populations of thirteen-lined ground squirrels (McCarley 1966; Wistrand 1974; Vestal and McCarley 1984), recognition by association is an adequate mechanism to mediate the differential treatment of uterine siblings in this species. If natal burrows are not infiltrated by juveniles unrelated to residents, nestmates can learn each others' identity during their period of association and later discriminate sibs (i.e., nestmates) from nonsibs (i.e., nonnestmates). Social interactions that occur just prior to the time when asymmetrically related young first interact would be most crucial to the ontogeny of sibling identification in S. tridecemlineatus if this species fits the pattern seen in other organisms (e.g., Beer 1970; Michener 1974; Beecher et al. 1981; Holmes and Sherman 1982). Bekoff (1981) has discussed in detail the relationship between rearing familiarity and kin recognition. Although it is not known if the multiple mating that occurs in S. tridecemlineatus (Schwagmeyer 1984) results in multiple insemination [as in S. beldingi (Hanken and Sherman 1981)], discrimination of full- from maternal half-sibs, if it occurs, would probably not be based on the association mechanism, because these relatives share both a common uterine and natal burrow environment.

It is not yet possible to present a fine-grained analysis for any taxon of how inter-specific differences in kin recognition might parallel differences in species' social systems. However, a preliminary picture may be emerging for some ground squirrels. In populations of $S$. beldingi (Sherman 1977, 1980, $1981 \mathrm{a}, 1981$ b), S. parryii (McLean 1982, 1984), and S. richardsonii (Yeaton 1972; Michener 1973, 1979, 1981; Michener and Michener 1977; Davis 1984), spatial association and home range overlap are greater and social interactions more frequent between female group members than between female $S$. tridecemlineatus. Thus, one finds that more complex recognition abilities (i.e., those that are not based simply on familiarity learned during association) parallel increased social complexity, as measured by spatial association and the frequency of social encounters.

\section{Olfaction and sibling recognition}

Olfaction mediates social relationships in several ground squirrel species (Kivett et al. 1976; Harris and Murie 1982) and it appears critical to sibling 
identification in $S$. tridecemlineatus. The recognition process depends on both the production of phenotypes that make individuals (or groups of individuals) distinct and the discrimination of those phenotypes by individuals attempting to identify conspecifics. Although the production component was not addressed here (see Beecher 1982; Lacy and Sherman 1983 for recent treatments of the production component), the olfactory-impairment technique reveals something about the discrimination component. Prior to treatment, familiar young were less exploratory than unfamiliar young (Fig. 1), and sibling recognition was inferred on the basis of this between-group difference in exploratory interactions. Following treatment, however, the between-group difference disappeared as exploratory interactions dropped to about equal levels for both familiar and unfamiliar pairs (Fig. 2). Thus, differential treatment did not occur when olfaction was impaired, as verified independently by the peanut butter preference test (see Methods). Because impaired animals ate food and gained weight like control subjects, because impaired animals exhibited species-typical social interactions during arena tests (albeit at a reduced rate), and because I could not readily distinguish impaired from control animals during casual observations in the colony room, it is unlikely that impaired animals were simply ill and thus reduced their frequency of exploratory encounters because of a general malaise. Whereas the impairment experiment reveals the importance of olfactory cues it does not indicate the component of olfaction (e.g., the primary olfactory system, the vomeronasal system) that mediates recognition, because the destructive effects of zinc sulfate on the olfactory system require histological verification (Winans and Powers 1977).

Other species can also identify siblings with olfactory cues as demonstrated experimentally. Cascade frog tadpoles (Rana cascadae) associate preferentially with sibs over nonsibs based on waterborne chemical cues that are probably sensed by olfaction or taste (Blaustein and O'Hara 1982). Interpreting data from a zinc sulfate experiment, Porter et al. (1978) conclude that spiny mice (Acomys cahirinus) identify their sibs primarily by olfactory information. Olfactory cues are even sufficient for sibling recognition in humans (Porter and Moore 1981).

Acknowledgements. I wish to thank each of the following people who were instrumental in my research. W. Benninghoff and the staff of the Matthaei Botanical Gardens assisted me in acquiring animals. D. Bushberg, D. DiMario, and L. Shellberg helped in trapping, maintaining, and testing animals. M. Leh- man and S. Winans discussed and developed the zinc sulfate treatment that I used. A. Blaustein, T. Schwagmeyer, and P. Sherman reviewed earlier versions of this paper, and comments from two anonymous reviewers were also valuable. P. Sherman discussed kin recognition extensively with me. My research was supported in part by funds from the Department of Psychology and the Office of the Dean, College of Literature, Science, and the Arts at the University of Michigan.

\section{References}

Alberts JR (1974) Producing and interpreting experimental olfactory deficits. Physiol Behav 12:657-670

Alexander RD (1979) Darwinism and human affairs. University of Washington Press, Seattle

Alexander RD, Borgia G (1978) Group selection, altruism, and the levels of organization of life. Annu Rev Ecol Syst $9: 449-474$

Bateson PPG (1980) Optimal outbreeding and the development of sexual preferences in Japanese quail. Z Tierpsychol 53:231-244

Bateson PPG (1982) Preferences for cousins in Japanese quail. Nature 295:236-237

Bateson PPG (1983) Optimal outbreeding. In: Bateson PPG (ed) Mate choice. Cambridge University Press, Cambridge, pp 257-277

Beecher MD (1982) Signature systems and kin recognition. Am Zool 22:477-490

Beecher MD, Beecher IM, Nichols SH (1981) Parent-offspring recognition in bank swallows Riparia riparia: II. Development and acoustic basis. Anim Behav 29:95-101

Beer CG (1970) Individual recognition of voice in the social behavior of birds: In: Rosenblatt J, Beer C, Hinde R (eds) Advances in the study of behavior, vol 3. Academic Press, New York, pp 27-74

Bekoff M (1981) Mammalian sibling interactions: genes, facilitative environments, and the coefficient of familiarity. In: Gubernick DJ, Klopfer PH (eds) Parental care in mammals. Plenum, New York, pp 307-346

Betts BJ (1976) Behaviour in a population of Columbian ground squirrels, Spermophilus columbianus columbianus. Anim Behav 24:652-680

Blaustein AR (1983) Kin recognition mechanisms: phenotypic matching or recognition alleles? Am Nat 121:749-754

Blaustein AR, O'Hara RK (1981) Genetic control for sibling recognition? Nature 290:246-248

Blaustein AR, O'Hara RK. (1982) Kin recognition cues in Rana cascadae tadpoles. Behav Neural Biol 36:77-87

Breed MD (1983) Nestmate recognition in honey bees. Anim Behav 31:86-91

Buckle GR, Greenberg L (1981) Nestmate recognition in sweat bees (Lasioglossum zephyrum): does an individual recognize its own odour or only odours of its nestmates? Anim Behav 29:802-809

Burtt EH Jr (1977) Some factors in the timing of parent-chick recognition in swallows. Anim Behav 25:231-239

Carter-Saltzman L, Scarr-Salapatek S (1975) Blood group, behavioral, and morphological differences among dizygotic twins. Soc Biol 22:372-374

Davis LS (1982) Sibling recognition in Richardson's ground squirrels (Spermophilus richardsonii). Behav Ecol Sociobiol $11: 65-70$

Davis LS (1984) Behavioral interactions of Richardson's ground squirrels: asymmetries based on kinship. In: Muric JO, Michener GR (eds) Biology of ground-dwelling squirrels: annual cycles, behavioral ecology, and sociality. University of Nebraska Press, Lincoln (in press) 
Dawkins R (1982) The extended phenotype. Freeman, Oxford

Dewsbury DA (1982) Avoidance of incestuous breeding between siblings in two species of Peromyscus mice. Biol Behav $7: 157-169$

Dunford C (1977a) Social system of round-tailed ground squirrels. Anim Behav 25:885-906

Dunford C (1977b) Kin selection for ground squirrel alarm calls. Am Nat 111:782-785

Getz WM, Smith KB (1983) Genetic kin recognition: honey bees discriminate between full and half-sisters. Nature 302:147-148

Greenberg L (1979) Genetic component of bee odor in kin recognition. Science 206:1095-1097

Hamilton WD (1964) The genetical evolution of social behaviour, I and II. J Theor Biol 7:1-52

Hamilton WD (1972) Altruism and related phenomena, mainly in social insects. Annu Rev Ecol Syst 3:193-232

Hanken J, Sherman PW (1981) Multiple paternity in Belding's ground squirrel litters. Science 212:351-353

Harris MA, Murie JO (1982) Responses to oral gland scents from different males in Columbian ground squirrels. Anim Behav 30:140-148

Hölldobler B, Michener CD (1980) Mechanisms of identification and discrimination in social hymenoptera. In: Markl $H$ (ed) Evolution of social behavior: hypotheses and empirical tests. Dahlem Konferenzen 1980. Verlag Chemie, Weinheim, pp 35-58

Holmes WG, Sherman PW (1982) The ontogeny of kin recognition in two species of ground squirrels. Am Zool 22:491517

Holmes WG, Sherman PW (1983) Kin recognition in animals. Am Sci 71:46-55

Hoogland JL (1982) Prairie dogs avoid extreme inbreeding. Science 215:1639-1641

Hoogland JL, Sherman PW (1976) Advantages and disadvantages of bank swallow (Riparia riparia) coloniality. Ecol Monogr 46:33-58

Kivett VK, Murie JO, Steiner AL (1976) A comparative study of scent-gland location and related behavior in some Nearctic ground squirrel species (Sciuridae): an evolutionary approach. Can J Zool 54:1294-1306

Lacy RC, Sherman PW (1983) Kin recognition by phenotype matching. Am Nat 121:489-512

McCarley H (1966) Annual cycle, population dynamics, and adaptive behavior of Citellus tridecemlineatus. J Mammal 47:294-316

McLean IG (1982) The association of female kin in the Arctic ground squirrel Spermophilus parryii. Behav Ecol Sociobiol 10:91-99

McLean IG (1983) Paternal behaviour and killing of young in Arctic ground squirrels. Anim Behav 31:32- 44

McLean IG (1984) Spacing behavior of female ground squirrels. In: Murie JO, Michener GR (eds) Biology of ground-dwelling squirrels: annual cycles, behavioral ecology, and sociality. University of Nebraska Press, Lincoln (in press)

Michener GR (1973) Field observations on the social relationships between adult female and juvenile Richardson's ground squirrels. Can J Zool 51:33-38

Michener GR (1974) Development of adult-young identification in Richardson's ground squirrel. Dev Psychobiol $7: 375-384$

Michener GR (1979) Spatial relationships and social organization of adult Richardson's ground squirrels. Can J Zool 57:125-129

Michener GR (1981) Ontogeny of spatial relationships and social behaviour in juvenile Richardson's ground squirrels. Can J Zool 59:1666-1676
Michener GR (1983) Kin identification, matriarchies, and the evolution of sociality in ground-dwelling sciurids. In: Eisenberg JF, Kleiman DG (eds) Advances in the study of mammalian behavior. Special publication 7, American Society of Mammalogists, pp 528-572

Michener GR, Michener DR (1977) Population structure and dispersal in Richardson's ground squirrels. Ecology 58:359-368

Michener GR, Sheppard DH (1972) Social behavior between adult Richardson's ground squirrels (Spermophilus richardsonii) and their own and alien young. Can J Zool 50:1343-1349

Murie JO, Harris MA (1984) The history of individuals in a population of Columbian ground squirrels: source, settlement, and site attachment. In: Murie JO, Michener GR (eds) Biology of ground-dwelling squirrels: annual cycles, behavioral ecology, and sociality. University of Nebraska Press, Lincoln (in press)

Murphy MR (1976) Olfactory impairment, olfactory bulb removal, and mammalian reproduction. In: Doty RL (ed) Mammalian olfaction, reproductive processes, and behavior. Academic Press, New York, pp 95-117

Porter RH, Moore JD (1981) Human kin recognition by olfactory cues. Physiol Behav 27:493-495

Porter RH, Wyrick M (1979) Sibling recognition in spiny mice (Acomys cahirinus): influence of age and isolation. Anim Behav 27:761-766

Porter RH, Wyrick M, Pankey J (1978) Sibling recognition in spiny mice (Acomys cahirinus). Behav Ecol Sociobiol 3:61-68

Porter RH, Tepper VJ, White DM (1981) Experiential influences on the development of huddling preferences and "sibling" recognition in spiny mice. Dev Psychobiol 14:375-382

Ridley M, Grafen A (1981) Are green beard genes outlaws? Anim Behav 29:954-955

Rongstad OJ (1965) A life history study of thirteen-lined ground squirrels in southern Wisconsin. J Mamm 46:76-87

Rothstein SI, Barash DP (1983) Gene conflicts and the concepts of outlaw and sheriff alleles. J Social Biol Struct (in press)

Salzen EA, Cornell JM (1968) Self-perception and species recognition in birds. Behaviour 30:44-65

Schwagmeyer PL (1979) The function of alarm calling behavior in Spermophilus tridecemlineatus, the thirteen-lined ground squirrel. PhD thesis, University of Michigan, Ann Arbor

Schwagmeyer PL (1980) Alarm calling behavior of the thirteenlined ground squirrel, Spermophilus tridecemlineatus. Behav Ecol Sociobiol 7:195-200

Schwagmeyer PL (1984) Multiple mating and intersexual selection in ground squirrels. In: Murie JO, Michener GR (eds) Biology of ground-dwelling squirrels: annual cycles, behavioral ecology, and sociality. University of Nebraska Press, Lincoln (in press)

Sheppard DH, Yoshida SM (1971) Social behavior in captive Richardson's ground squirrels. J Mammal 52:793-799

Sherman PW (1977) Nepotism and the evolution of alarm calls. Science 197:1246-1253

Sherman PW (1980) The limits of ground squirrel nepotism. In: Barlow GW, Silverberg $\mathbf{J}$ (eds) Sociobiology: beyond nature/nurture? Westview Press, Boulder, pp 505-544

Sherman PW (1981 a) Reproductive competition and infanticide in Belding's ground squirrels and other organisms. In : Alexander RD, Tinkle DW (eds) Natural selection and social behavior: recent research and new theory. Chiron Press, New York, pp 311-331

Sherman PW (1981 b) Kinship, demography, and Belding's ground squirrel nepotism. Behav Ecol Sociobiol $8: 251-$ 259 
Shields WM (1982) Philopatry, inbreeding, and the evolution of sex. State University of New York Press, Albany

Steiner AL (1970) Étude descriptive de quelques activités et comportements de base de Spermophilus columbianus columbianus (Ord). II. Vie de groupe. Rev Comp Anim 4:23-42

Vestal BM, McCarley H (1984) Spatial and social relationships among relatives in thirteen-lined ground squirrel populations. In: Murie JO, Michener GR (eds) Biology of grounddwelling squirrels: annual cycles, behavioral ecology, and sociality. University of Nebraska Press, Lincoln (in press)

Vidal J-M (1982) "Auto-imprinting": effects of prolonged isolation on domestic cocks. J Comp Physiol Psych 96:256267
Waldman B, Adler K (1979) Toad tadpoles associate preferentially with siblings. Nature 282:611-613

West Eberhard MJ (1975) The evolution of social behavior by kin selection. Q Rev Biol 50:1-33

Winans SS, Powers JB (1977) Olfactory and vomeronasal deafferentation of male hamsters: histological and behavioral analyses. Brain Res 126:325-344

Wistrand $H$ (1974) Individual, social, and seasonal behavior of the thirteen-lined ground squirrel (Spermophilus tridecemlineatus). J Mammal 55:329-347

Yeaton RI (1972) Social behavior and social organization in Richardson's ground squirrel (Spermophilus richardsonii) in Saskatchewan. J Mammal 53:139-147 